\title{
Reconstruction of Large Mandibular Defects Using Autologous Tissues Generated from In Vivo Bioreactors
}

Alexander M. Tatara ${ }^{a}$, Sarita R. Shah", Nagi Demian ${ }^{b}$, Tang $\mathrm{Ho}^{c}$, Jonathan Shum ${ }^{\mathrm{b}}$, Jeroen J.J.P. van den Beucken ${ }^{d}$, John A. Jansen ${ }^{d}$, Mark E. Wong ${ }^{b}$, and Antonios G. Mikos ${ }^{a^{*}}$

${ }^{a}$ Department of Bioengineering, Rice University, 6500 Main Street, Suite 135, Houston, Texas 77030

${ }^{b}$ Department of Oral and Maxillofacial Surgery, University of Texas Health Science Center at Houston, 7500 Cambridge Street, Houston, TX 77054

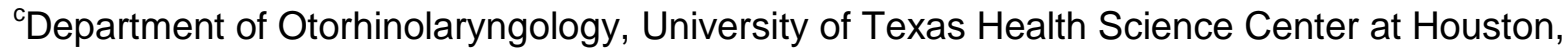
6411 Fannin Street, Houston, Texas 77030

dDepartment of Biomaterials, Radboud University Medical Center, Philips v Leijdenln 25, 6525 EX NIJMEGEN, The Netherlands

${ }^{*}$ Corresponding author

Antonios G. Mikos, PhD

Department of Bioengineering, MS-142

BioScience Research Collaborative

Rice University

6500 Main Street

Houston, TX 77030

e-mail:mikos@rice.edu;

Tel: (713) 348-5355

Fax: (713) 348-4244 


\section{Abstract}

Reconstruction of large mandibular defects is clinically challenging due to the need for donor tissue of appropriate shape and volume to facilitate high fidelity repair. In order to generate large vascularized tissues of custom geometry, bioreactors were implanted against the rib periosteum of 3-4 year-old sheep for nine weeks. Bioreactors were filled with either morcellized autologous bone, synthetic ceramic particles, or a combination thereof. Tissues generated within synthetic graft-filled bioreactors were transferred into a large right-sided mandibular angle defect as either avascular grafts $(n=3)$ or vascularized free flaps $(n=3)$. After twelve additional weeks, reconstructed mandibular angles were harvested and compared to contralateral control angles. Per histologic and radiologic evaluation, a greater amount of mineralized tissue was generated in bioreactors filled with autologous graft although the quality of viable bone was not significantly different between groups. Genetic analyses of soft tissue surrounding bioreactor-generated tissues demonstrated similar early and late stage osteogenic biomarker expression (Runx2 and Osteocalcin) between the bioreactors and rib periosteum. Although no significant differences between the height of reconstructed and control mandibular angles were observed, the reconstructed mandibles had decreased bone volume. There were no differences between mandibles reconstructed with bioreactor-generated tissues transferred as flaps or grafts. Tissues used for mandibular reconstruction demonstrated integration with native bone as well as evidence of remodeling. In this study, we have demonstrated that synthetic scaffolds are sufficient to generate large volumes of mineralized tissue in an in vivo bioreactor for mandibular reconstruction.

Keywords: In vivo; bioreactor; tissue engineering; craniofacial 


\section{Introduction}

Loss of mandibular bone can occur due to tumor resection, trauma, or congenital malformation and presents a clinical challenge to repair. The free fibular flap is the current standard-of-care for the reconstruction of large mandibular defects [1]. In this procedure, a piece of fibular bone with accompanying artery and vein is harvested from the patient. The harvested tissue is then trimmed and shaped in the operating room such that its dimensions roughly approximate that of the mandibular defect. The flap can then be inserted into the defect and vascularized by anastomoses to local facial arteries and veins. Cases of large defects and/or defects of complex geometry can be difficult to repair with the free fibular flap [1]. In addition, harvest of the fibula can result in donor site morbidity, including nerve damage, pain with activity, decreased range of motion, and lower extremity ischemia [2].

To mitigate these complications, in vivo bioreactor approaches are currently being explored for repair of large craniofacial defects [3]. In this strategy, bioreactors of customizable size and geometry are implanted at a site distal to the defect with the goal of stimulating the growth of mineralized tissues. These tissues can then be harvested and transferred to the craniofacial defect as autologous, vascularized free tissue flaps of customizable geometry for high fidelity repair. In combination with exogenous growth factors, this strategy has been employed in a clinical setting with some limited success $[3,4]$. However, malignancy is a contraindication for the use of growth factors [5], and malignant tumor resection is a common cause of large mandibular defects [6]. Therefore, in order to clinically translate this strategy, an in vivo bioreactor approach generating mineralized tissues in the absence of exogenous growth factors is desirable. Lastly, bioreactors must be filled with appropriate scaffold material in order to support viable tissue growth [7]. Morcellized autologous bone from a donor site, such as the iliac crest, is the most common source of scaffold material [8]. It would be advantageous to reduce or eliminate the need for autologous bone to minimize donor site morbidity. 
Here, we report on the design of a strategy that generates vascularized free tissue flaps from bioreactors implanted against the periosteum of the rib using morcellized autologous bone, synthetic graft, or a combination thereof as scaffold material. The feasibility of this approach for the generation of tissues as well as the use of these tissues in reconstruction of a large mandibular defect in an ovine model was demonstrated in a study with 4 month-old sheep [9]. However, the previous study was conducted in young sheep and was underpowered for statistical analyses. In the present study, the effect of scaffold material (autologous graft versus synthetic graft) on the quality and quantity of hard and soft tissues (as well as the soft tissue envelope surrounding these tissues) grown in implanted bioreactors was characterized by radiologic, histologic, and molecular methods in 3-4 year-old animals. Although not a direct comparison, the effect of sheep age on bioreactor tissue generation was studied given that the same strategy was previously applied in 4 month-old sheep [9]. In addition, tissues grown from bioreactors filled with synthetic graft were transferred as either avascular grafts or vascularized free tissue flaps to a large defect of the right mandibular angle. The reconstructed mandibular angle was compared by radiologic and histologic methods to the undisturbed contralateral angle to measure the effect of reconstruction with vascularized tissues versus avascular grafts.

In this study, we hypothesized that 1) both autologous bone (the current graft gold standard) and synthetic graft would be capable of supporting formation of viable mineralized tissue within in vivo bioreactors and that 2) bioreactor-generated tissues transferred as vascularized free flaps would result in repaired mandibles more similar to native mandible than avascular grafts. The objectives of the current study were to 1) evaluate the capacity of different scaffold materials to form viable mineralized tissue in an in vivo bioreactor setting and 2) to determine the efficacy of repairing a large mandibular defect with tissues generated in an in vivo bioreactor initially filled with synthetic graft scaffold, with tissue transferred as either an avascular graft or vascularized free flap. Tissues from bioreactors filled with synthetic graft were 
chosen for use in reconstruction as synthetic scaffold minimizes the need for autologous tissue harvest and potential donor site morbidity.

\section{Methods and Materials}

\subsection{Bioreactor Implantation}

Six female sheep (age 3-4 years, ranging from 34.6-55.5 kg in weight) were used in a protocol approved by the Animal Welfare Committee of the University of Texas at Houston Health Science Center and the Animal Care and Use Review Office of the Department of Defense. Bioreactor implantation was performed per established methods [7, 9, 10]. Briefly, animals were anesthetized and intubated. Under sterile operating conditions, two incisions of up to $15 \mathrm{~cm}$ in length were made over the rib cage of the right flank. After dissecting through abdominal fat, fascia, and muscle, the periosteum of the ribs was lifted and 5-6 cm segments of rib were removed with care to minimize disturbance to the cambium. Segments were removed from either the $2^{\text {nd }}, 4^{\text {th }}, 6^{\text {th }}$, and $8^{\text {th }}$ rib, or $3^{\text {rd }}, 5^{\text {th }}, 7^{\text {th }}$, and $9^{\text {th }}$ rib. Portions of removed rib were morcellized in a bone mill (R. Quéntin Bone Mill, KLS Martin, Mühlheim, Germany). Bioreactors consisted of an open-faced $1 \mathrm{~cm} \times 1 \mathrm{~cm} \times 4 \mathrm{~cm}$ chamber of polymethylmethacrylate with an ethylene-vinyl acetate cuff with $\sim 1 \mathrm{~cm}$ overhang on each side for suturing (Fig. 1). These bioreactors were implanted against the periosteum of the removed rib segments with the open face adjacent to the periosteum. Each animal received four bioreactors; the scaffold used in these bioreactors was either morcellized autograft (AG), synthetic graft (SG), or a 50/50 v/v mixture of $A G$ and $S G$ (Mix). AG was packed at a consistent volume of $0.55 \mathrm{~g} / \mathrm{L}$. SG consisted of $85 \%$ beta-tricalcium phosphate/15\% hydroxyapatite biphasic ceramic porous granules with average diameter of $1.6-3.2 \mathrm{~mm}$, porosity of $80 \%$, and average pore size of $500 \mu \mathrm{m}$, as reported by the manufacturer (MASTERGRAFT ${ }^{\circledR}$ Granules, Medtronic, Dublin, Ireland). Each animal received bioreactors filled with AG (1), Mix (1), and SG (2), assigned in randomized rib order. Bioreactors were sutured such that the open face was against the cambium of the periosteum. 
The muscle, fascia, and skin were closed and animals were monitored post-operatively for signs of discomfort or adverse events.

\subsection{Mandibular Reconstruction}

Nine weeks following bioreactor implantation, animals were anesthetized and intubated for bioreactor tissue harvest and mandibular reconstruction. Two incisions of up to $15 \mathrm{~cm}$ in length were made over the rib cage of the right flank. A dissection was performed to uncover the implanted bioreactors. The AG, Mix, and one of the two SG bioreactors were harvested. Sterile disposable $3 \mathrm{~mm}$ biopsy punches (Integra LifeSciences, Plainsboro, NJ) were used to take a sample of the soft tissue envelope covering the tissues within the bioreactors from the face of the tissue adjacent to the periosteum ("bottom"), from the face of the tissue adjacent to the top of the bioreactor ("top"), and from a face of the tissue adjacent to the side of the bioreactor ("side"). In some instances, tissue was unable to be sampled from a face due to thinness of the envelope or tissue (total $\mathrm{n}$ per group listed in Supplemental Table 1). These biopsies were placed in RNALater Stabilization Solution (Qiagen, Hilden, Germany) and stored per the manufacturer's instructions until further analysis. The remainder of the bioreactor-generated tissues were placed in 10\% neutral buffered formalin (NBF) (VWR International, West Chester, PA). The tissue from the remaining SG bioreactor was harvested as an avascular graft in the "graft" group ( $n=3$ animals) or as a vascularized free tissue flap with accompanying pedicle (internal mammary artery, vein, and nerve) in the "flap" group ( $n=3$ animals).

In order to resect the right mandibular angle, a $6 \mathrm{~cm}$ incision along the right inferior border of the mandible was made. After dissection to the bone, a $4 \mathrm{~cm}$ in length $\mathrm{x} 1 \mathrm{~cm}$ in height section of the angle was removed by dental bur as previously described [9]. The mandible was then reconstructed by plating the harvested flap or graft into the defect with a titanium midface plate and self-tapping titanium screws (KLS Martin, Mühlheim, Germany). As the angular defect was under minimal biomechanical load and not segmental, a single plate was considered 
sufficient for fixation. The bioreactor-generated tissues were fixed into the defect by tightly suturing the tissues to the plate. For animals in the flap group, an incision of up to $5 \mathrm{~cm}$ was made in the neck for vascular access. In side-to-side and end-to-side orientation, surgical anastomoses were performed under surgical microscopy (Leica Microsystems, Wetzlar, Germany) to attach the artery ( $1.5 \mathrm{~mm}$ in diameter) and vein ( $\sim .5 \mathrm{~mm}$ in diameter) of the free tissue flap to a branch of the external carotid artery and accompanying vein. Patency was confirmed by observing arterial pulsations. No anastomoses nor neck incisions were performed for animals in the graft group. The mandible and neck were closed and animals were monitored post-operatively for signs of discomfort or adverse events.

Twelve weeks after reconstruction, animals were euthanized. One animal was euthanized several days after twelve weeks in order to euthanize animals such that none would be housed alone, a requirement of housing sheep. Mandibles were harvested and placed in $10 \%$ NBF. All harvested tissues placed in $10 \%$ NBF were transferred to $70 \%$ ethanol (Koptec, King of Prussia, PA) after one week and stored at $4^{\circ} \mathrm{C}$ until further processing.

\subsection{Microcomputed Tomography}

Microcomputed tomography, a non-destructive imaging modality, was performed with a SkyScan 1172 microCT imaging system (SkyScan, Aartselaar, Belgium). From each hemimandible, a section of approximately $6 \mathrm{~cm}$ in length and $2 \mathrm{~cm}$ in height was created by diamond blade saw (South Bay Technologies, San Clemente, CA) to recover the reconstructed angle (right side) and contralateral control angle (left side). Bioreactor-generated tissue specimens and mandibular angles were imaged using an x-ray tube voltage of $59 \mathrm{kV}$ and current of $167 \mu \mathrm{A}$ with a $1 \mathrm{~mm}$ aluminum filter at a voxel size of $15.1 \mu \mathrm{m}$ (bioreactor specimens) and $17.1 \mu \mathrm{m}$ (mandibular specimens). The images were reconstructed for analysis using the software NRecon (version 1.6.9.18, SkyScan) and CTAn (version 1.15.4.0, SkyScan) with a 15\% beamhardening correction and a 65-255 binary threshold. 
For bioreactor-generated tissue specimens, a rectangular region of interest (ROI) was chosen such that the ROI had no overlap with area outside of the generated tissues. For mandibular specimens, a rectangular $\mathrm{ROI}$ within the cortex of the inferior border of the angle was chosen, such that there was no overlap with the trabecular bone outside of the cortex, inferior alveolar canal, nor soft tissue/muscle inferior to the inferior cortex (in other words, the most inferior mineralized border of the angle). The percentage of bone volume to total volume (BV/TV), trabecular number (Tb.N.), trabecular spacing (Tb.Sp.), and trabecular thickness (Tb.Th.) for each region of interest were calculated with CTAn software.

\subsection{Histology}

After non-destructive radiographic analysis, specimens were subjected to histology. All tissue specimens were embedded in polymethylmethacrylate. Briefly, non-decalcified specimens were serially dehydrated in ethanol solutions of increasing concentration (70-100\%) and then placed in a modified methylmethacrylate solution $(300 \mathrm{~mL}$ methylmethacrylate, $30 \mathrm{~mL}$ dibutylphthalate, and 5 g 2,-2'azobisisobutyronitrile) and allowed to polymerize over 1-2 weeks. Following polymerization, embedded specimens were sliced into $10 \mu \mathrm{m}$ sections by a microtome with a diamond blade (Leica Microsystems SP 1600, Nussloch, Germany), and stained with methylene blue/basic fuchsin. Sections were taken from the midpoint of the bioreactor-generated tissue specimens and from the midpoint along the length of the harvested mandibular angle such that the alveolar canal could be visualized along the superior border of the tissue. Three to four sections were made from each specimen. Images of sections were taken with a BX51 Olympus Slidescanner (Olympus Corporation, Tokyo, Japan).

\subsubsection{Quantitative Histological Scoring}

A quantitative histological scoring system was developed to further characterize scaffold properties (Table 1) as well as tissue properties (Table 2). Scoring of a randomly selected 
section from each bioreactor specimen ( $n=6$ per group) was performed by three blinded evaluators (SRS, EW, and BTS).

\subsubsection{Histomorphometry}

A randomly selected section from each bioreactor specimen ( $n=6$ per group) was subjected to histomorphometric analysis via ImageJ (National Institutes of Health, Bethesda, Maryland). Fractional depth as well as Synthetic Graft Surface Area and Bone Surface Area were calculated as described previously [9]. Fractional depth is a two-dimensional measurement reflecting the height of bone grown into the bioreactor $[7,9,10]$. Briefly, the open face of the chamber (adjacent to the periosteum) was defined as the $\mathrm{X}$ axis. The mean of distances between the furthest viable osteocyte perpendicular to the $X$ axis along $1 / 3,1 / 2$, and $2 / 3$ the length of the bioreactor, normalized by the height of the bioreactor $(1 \mathrm{~cm})$, was defined as the fractional depth. Specimens containing no viable mineralized tissue (as scored by three independent reviewers) were excluded from fractional depth analysis.

Angle height is a two-dimensional measurement taken from a randomly selected

mandibular section ( $n=3$ per experimental group, $n=6$ per contralateral control angle group). The inferior edge of the inferior alveolar canal was defined as the $\mathrm{X}$ axis. The mean of the distances between the furthest viable osteocyte along an axis parallel to the cortical plates and perpendicular to the edge of the inferior alveolar canal was measured at 1/3,1/2, and 2/3 the width of the inferior alveolar canal was defined as the angle height.

Thresholding was used to select and calculate the surface area of remaining SG and mineralized tissue. These surface areas were then normalized by the total surface area of the tissue generated in each bioreactor to calculate SG Surface Area and Bone Surface Area. 


\subsection{Quantitative Reverse Transcriptase Polymerase Chain Reaction}

To determine osteogenic gene expression levels, mRNA was isolated from biopsies of the soft tissue envelope surrounding the generated tissue in the bioreactors. Quantitative reverse transcriptase polymerase chain reaction (RT-qPCR) was performed on $3 \mathrm{~mm}$ biopsy samples from the top, side, and bottom of tissues by standard methodology. Samples of periosteum taken from native rib (three samples from two sheep each, $n=6$ ) were used as controls. Briefly, to recover and isolate mRNA, biopsy specimens were flash frozen in liquid nitrogen, crushed, placed in lysis buffer for 5 minutes (Buffer RLT, Qiagen, Hilden, Germany), shredded (QIAshredder, Qiagen) and collected (RNeasy Spin Column, Qiagen). Isolated mRNA was washed with Buffer RW1 (Qiagen), Buffer RPE (Qiagen), and 70\% ethanol, followed by elution in RNAse-free water and stored at $-80^{\circ} \mathrm{C}$ until cDNA synthesis.

Runx2 and Osteocalcin $(O C)$ were chosen as genes of interest due to expression in early and late osteogenesis, respectively [11], with GAPDH as a housekeeping gene. The forward and reverse primer sequences, validated for sheep in the literature [12, 13], were as follows: Runx2, 5' TCGCCTCACAAACAACCA 3', 5' AGGGACCTGCGGAGATTA 3'; OC, 5' AGATGCAAAGCCTGGTGATGC 3', 5' CTCCTGGAAGCCGATGTGGT 3'; and GAPDH, 5' GCAAGTTCCACGGCACAG 3', 5' GGTTCACGCCCATCACAA 3'. Reverse transcription was performed following manufacturer's instructions using Oligo(dT) 15 Primer (Promega, Madison, WI) and VeriScript Reverse Transcriptase (Affymetrix, Santa Clara, CA). With the subsequently generated cDNA, Quantitative PCR was then performed using forward and reverse primers and VeriQuest Fast SYBR Green (Affymetrix) with a 7300 Real-Time PCR System (Applied Biosystems, Foster City, CA).

\subsection{Statistical Analysis}

All statistics were performed in JMP Pro 11 (SAS Institute, Cary, NC). All tests were conducted with a 95\% confidence interval $(\alpha=0.05)$. Differences between groups for microCT 
measurements ( $n=6$ per group for bioreactor specimens; $n=3$ per reconstructed mandibular angle groups and $\mathrm{n}=6$ per control mandibular angle group), histomorphometric measurements ( $n=6$ per group for bioreactor specimens; $n=3$ per reconstructed mandibular angle groups and $\mathrm{n}=6$ per control mandibular angle group), and RT-qPCR data ( $\mathrm{n}$ per group reported in Supplemental Table 1) were compared using analysis of variance (ANOVA) combined with posthoc analysis via Tukey's Honestly Significant Difference test. Scores from quantitative histological scoring ( $\mathrm{n}=6$ per experimental group) were compared by Kruskal-Wallis with posthoc analysis via the Steel-Dwass test.

\section{Results}

\subsection{Animal Care and Gross Observation}

Bioreactors were filled with scaffold material and successfully implanted in each animal (Fig. 2A). Implantation was well tolerated in all animals with no adverse events. After nine weeks of implantation, bioreactors were harvested with accompanying tissue and biopsies were taken from the soft tissue envelope (Fig. 2B-D). Tissues generated from SG-filled bioreactors were transferred into a mandibular angle defect (Fig. 2E and 2F). Following bioreactor harvest and mandibular reconstruction, two sheep (one in the graft group and one in the flap group) had edema at the site of reconstruction that resolved without intervention after several days. Animals and surgical sites were closely monitored but exhibited no signs of pain or infection.

Upon euthanasia and tissue harvest, one animal presented with dislocation of the implanted tissue into the fascia of the neck (flap group, Supplemental Fig. 1). It was unclear at which point over the twelve-week period that the tissue became dislocated. All other animals showed retention of the implanted tissue at the mandibular defect site. 


\subsection{Bioreactor-generated Tissues}

\subsubsection{Microcomputed Tomography}

MicroCT was performed on bioreactor specimens (Fig. 3A) to calculate BV/TV, Tb.N., Tb.Sp., and Tb.Th (Fig. 4). In bioreactor specimens, BV/TV was significantly greater for AG compared to $S G(50.7 \%$ versus $37.2 \% ; p=0.029)$. Tb.N. was also significantly greater for $A G$ compared to both Mix and SG (3.26 1/mm versus 1.83 and $1.471 / \mathrm{mm}$, respectively; $p<0.001$ and $\mathrm{p}<0.001)$. Tb.Sp. and Tb.Th. were significantly greater in Mix and SG groups compared to AG groups ( 0.37 and $0.39 \mathrm{~mm}$ versus $0.16 \mathrm{~mm} ; \mathrm{p}=0.012$ and $\mathrm{p}=0.006$, and 0.23 and $0.26 \mathrm{~mm}$ versus $0.16 \mathrm{~mm}$, respectively; $p=0.012$ and $p=0.002$ ).

\subsubsection{Histologic Analyses}

Histologic sections were taken from the center of bioreactor specimens (Fig. 2B). High magnification images demonstrate new viable bone formation in specimens from the AG (Fig. 5A), Mix (Fig. 5B), and SG (Fig. 5C) groups. However, not all specimens demonstrated new viable bone. In Figure 6, high magnification images are shown from within the Mix group to compare specimens in which new viable bone formation occurred (Fig. $6 \mathrm{~A}$ ) to specimens with only fibrovascular infiltration (Fig. 6B). Several bioreactor specimens presented cartilaginous tissue suggestive of endochondral ossification (Fig. 6C).

By quantitative histological scoring, SG and Mix groups showed significantly greater SG Intactness and SG Substrate scores compared to AG groups (Fig. 7A and 7B). Likewise, Mix and AG groups showed significantly greater AG Substrate scores compared to SG groups (Fig. 7C). AG, Mix, and SG bioreactors contained new viable mineralized tissue in 2/6, 3/6, and 4/6 of specimens, respectively. However, there were no statistically significant differences between any scaffold groups for any of the tissue scores (Fig. 7D-F).

Fractional depth of the bioreactors showed similar results, irrespective of graft material (Fig. 8A). SG and Mix groups showed significantly greater remaining SG Surface Area 
compared to AG groups (23.4 and $21.6 \%$ versus $1.9 \% ; p<0.001$ and $p=0.002)$ (Fig. $8 B$ ). The non-zero average in the AG group $(1.9 \%+/-2.1 \%)$ is attributed to slight staining/thresholding artifacts and has been previously noted [9]. AG showed significantly greater Bone Surface Area than SG (23.3\% versus $8.0 \% ; p=0.014)$ (Fig. $8 \mathrm{C})$.

\subsection{3. $R T-q P C R$}

In order to better characterize the soft tissue envelope surrounding the tissues generated within the in vivo bioreactors, RT-qPCR was performed on two biomarkers expressed by early pre-osteoblasts (Runx2) as well as mature functional osteoblasts $(O C)$ [11]. For either gene, there were no statistically significant differences between groups based on sampling site (top, bottom, or side) or scaffold type, nor statistically significant differences between the soft tissue envelope and the native periosteum (Fig. 9 and Supplemental Table 1).

\subsection{Reconstructed Mandibles}

\subsubsection{Microcomputed Tomography}

The inferior cortex of the reconstructed and control mandibular angles was analyzed by microCT (Figs. 10A and 11). Control mandibular angles showed significantly greater BV/TV than either reconstructed groups (99.89\% versus 82.91 and $78.73 \%$ for grafts and flaps, respectively; $\mathrm{p}=0.018$ and $\mathrm{p}=0.005)$. Angles reconstructed by flap transfer showed significantly greater Tb.Sp. than control $(0.30 \mathrm{~mm}$ versus $0.05 \mathrm{~mm} ; \mathrm{p}=0.002)$. Similar Tb.N. and Tb.Th values were observed between reconstructed and control angles.

As all transferred tissues were generated using SG bioreactors, SG tissues (harvested at nine weeks) were compared to the inferior cortex of reconstructed mandibles (transferred after nine weeks in bioreactors, followed by twelve weeks in the mandible) (Fig. 12). Compared to SG, grafts and flaps both showed significantly greater BV/TV (82.9 and $78.7 \%$ versus $37.2 \%$; $\mathrm{p}<0.001$ and $\mathrm{p}<0.001)$ and Tb.Th $(0.40$ and $0.49 \mathrm{~mm}$ versus $0.26 \mathrm{~mm} ; \mathrm{p}=0.007$ and $\mathrm{p}<0.001)$. 
The graft group showed significantly lower Tb.Sp. $(0.18 \mathrm{~mm}$ versus $0.39 \mathrm{~mm} ; p=0.024)$ and significantly greater Tb.N. (2.07 1/mm versus $1.471 / \mathrm{mm} ; \mathrm{p}=0.012)$ compared to SG.

\subsubsection{Histologic Analysis}

Coronal sections were taken from the mandibular angle for histologic analysis (Fig. 10B). After a total of twenty-one weeks of implantation, there remained unresorbed SG in reconstructed mandibular angles as demonstrated in high magnification images (Fig. 13). The dislocated tissue found in the neck fascia of a single flap animal contained viable mineralized tissue as well as unresorbed SG (Supplemental Fig. 1C). The angle height of reconstructed mandibular angles and controls (Fig. 14) showed similar results, irrespective of type of reconstruction technique.

\section{Discussion}

The ability to consistently generate an autologous free tissue bone flap of custom geometry with minimum donor site morbidity would be a major advancement for reconstructive surgery. In this study, we evaluated the effects of scaffold (autologous versus a synthetic ceramic) on generated tissues, as well as reconstruction of a large mandibular defect using tissues generated in bioreactors filled with synthetic graft as either avascular grafts or vascularized flaps. Specimens were evaluated radiologically and histologically. In addition, the soft tissue envelope surrounding bioreactor-generated tissues was molecularly analyzed for expression of early and late osteogenic markers. In brief, bioreactors filled with autologous graft generated more mineralized tissue but there were no differences by histological scoring of tissue quality between scaffold types. Although mandibular angles reconstructed with bioreactor-generated tissues had decreased height compared to contralateral native angles, these differences were not statistically significant. The cortex of mandibles reconstructed as vascularized flaps was less dense than native mandibulocortex. 
In contrast to other work in the field in which bioreactors are implanted intramuscularly [3], the rib periosteum was chosen as the site of in vivo bioreactor implantation in this study. While the muscle is a highly vascularized tissue, bioreactors implanted within the muscle in this model without addition of exogenous growth factors resulted in the generation of fibrovascular tissue, rather than mineralized tissue [14]. In addition, by implanting a non-porous, nonpermeable bioreactor consisting of five solid faces and one face communicating with the periosteum, this experimental design allows for infiltration of cell populations from only one direction. It was found that after nine weeks of implantation, without the use of any exogenous growth factors, cell populations (speculated to originate from the periosteum) were able to migrate through the bioreactors and produce new tissues (Figs. 5 and 6). While this study was not designed to analyze the mechanism of bone formation within the bioreactors, cartilaginous tissue suggesting endochondral ossification was observed at the border between fibrous tissue and mineralized tissue in several specimens (Fig. 6C). Although it is known that mesenchymal stem cells from rib periosteum undergo endochondral ossification during the normal fracture repair process [15], additional studies will need to be performed to further elucidate the mechanism of bone formation within bioreactors placed against the rib. If these tissues demonstrate integration with native bone and remodeling after transfer to a mandibular defect, the mechanism of bone formation during bioreactor implantation may be of lesser clinical importance.

While autologous bone is considered the gold standard for graft material, the harvest of autograft requires an additional procedure and is associated with donor site morbidity [8]. Therefore, synthetic grafts have been explored to expand or even entirely replace autograft with success in craniofacial surgery $[16,17]$. In this study, specimens from the SG group showed significantly less BV/TV (Fig. 4A) compared to the AG group. The AG group also demonstrated significantly greater Tb.N. and significantly less Tb.Sp. and Tb.Th. compared to the syntheticgraft containing groups (Fig. 4B-D). One explanation for these differences is the inherent 
differences in the scaffold materials used in this study. As can be seen histologically in the Mix and SG specimens in Figures 3 and 5, the width of radiopaque synthetic scaffold between pores within the particles can be wide, especially compared to the distance between trabeculae or morcellized autograft particles (demonstrated in the AG specimen in Figures 3 and 5). Therefore, while there is a greater number of trabeculae or particles in AG specimens (Tb.N.), the average thickness of radiopaque particles is higher in synthetic-graft containing groups (Tb.Th.) given the wide "struts" between pores in the ceramic architecture. Similarly, the thinner and more numerous radiopaque objects in AG groups pack more densely than the unresorbed synthetic graft, resulting in less space (Tb.Sp.) between individual objects in the AG group compared to synthetic graft-containing groups. Compared to previously reported sheep trabecular bone values [18], the bioreactor groups in the present study generally had greater BV/TV, Tb.N., and Tb.Th., and decreased Tb.Sp. In an analysis of the correlation between microCT parameters and mechanical strength in ovine bone, BV/TV, Tb.N., and Tb.Th. were found to be positively correlated with increasing mechanical properties, and Tb.Sp. was negatively correlated with increasing mechanical properties [18]. This suggests that the tissues grown within the bioreactor may behave similarly to corticocancellous bone, but mechanical analysis will need to be performed for definitive analysis.

In addition to decreased BV/TV, the SG group also had significantly less Bone Surface Area (Fig. 8C) compared to the AG group. However, neither measurement distinguishes viable bone tissue from non-viable bone graft. Fractional depth, a measurement of the distance between the base of the bioreactor and the furthest viable osteocyte normalized by the height of the bioreactor, showed no significant differences between groups (Fig. 8A). Under a scoring system designed to differentiate between viable and non-viable mineralized tissue (Table 2), there were no statistically significant differences in tissue scores between scaffolds (Fig. 7D-F). In fact, although not a statistically significant finding, bioreactors filled with SG more often contained viable mineralized tissue than Mix or AG groups (4/6, 3/6, and 2/6, respectively). 
These data are corroborated by a previous study using in vivo bioreactors in an ovine model in which a greater ratio of SG:AG was correlated with increasing fractional depth of bone [9]. A greater degree of mineralization may occur in SG-containing bioreactors due to local release of calcium and phosphate ions during the degradation of beta-tricalcium phosphate, which degrades much more rapidly than morcellized autologous bone. Similar biphasic beta-tricalcium phosphate/hydroxyapatite particles (40:60) have previously been demonstrated to be osteoinductive in ectopic ovine models [19]. Overall, all three scaffold groups were capable of supporting growth of mineralized tissue inside of the bioreactor.

In this study, it was noted that a distinct soft tissue envelope developed around the inner tissues supported by the scaffold (Fig. 2D). Biomaterials can induce a variety of different soft tissue responses, ranging from scar-like fibrous capsules to osteogenic membranes [20]. The inner walls of the bioreactors, which have contact with the growing tissues, are made of polymethylmethacrylate. As part of a two-stage reconstruction strategy, space maintainers made of polymethylmethacrylate have been demonstrated to generate an osteogenic membrane when placed in a bony defect [20]. Therefore, genetic analysis of the soft tissue envelope was undertaken to measure osteogenic gene expression. Samples were taken from different distances to the periosteum: adjacent to the periosteum (bottom); along the side of the bioreactor (side); or at the face most distal from the periosteum (top). There were no statistically significant differences in Runx2 or $O C$ expression between scaffold types nor between spatial geometries (Supplemental Table 1). In addition, there were no significant differences between expression in soft tissue envelopes and periosteal tissue. This may indicate that the soft tissue envelope surrounding the tissues grown in the bioreactor has osteogenic potential similar to the periosteum; however, only two biomarkers were analyzed. Further molecular analysis for additional genes (such as osteogenic and angiogenic growth factors), surface markers, and isolating these cell populations for in vitro culture and expansion would further characterize the nature of this soft tissue envelope. 
With the goal of minimizing the need for autologous donor tissue, only tissues grown in SG-filled bioreactors were used for mandibular reconstruction. These tissues were transferred as vascularized flaps or avascular grafts after nine weeks of bioreactor implantation, which has been shown to be the optimal time period for the generation of mineralized tissue in this model [7]. After twelve weeks, a time previously established to be appropriate for evaluating tissue engineering strategies in the ovine mandibular angle model [9, 21], animals were euthanized and the angles were harvested. During defect creation, the angle was removed in a $4 \times 1 \mathrm{~cm}$ resection. Per angle height, a measurement of the length from the inferior alveolar canal to the farthest viable osteocyte along the inferior cortex (most inferior bony border), there were no significant differences between mandibles. However, microCT analysis of the inferior cortex demonstrated significantly lower BV/TV of reconstructed mandibles and flap specimens had significantly greater Tb.Sp. than the contralateral control specimens. The increased spacing and decreased bone volume suggest that the reconstructed mandibles are less dense in structure than native mandibulocortical bone. However, it is possible that the integrated tissues can continue remodeling after implantation. In fact, the radiologic changes the tissues undergo from when they are harvested from bioreactors (SG) to twelve weeks later when harvested from reconstructed mandibles (grafts and flaps) are significant and suggest active tissue remodeling (Fig. 12). It is also of note that the flaps and grafts were transferred as rectangular blocks (the given shape of the bioreactors, as seen in Figures 1 and 2) without additional trimming. Nevertheless, after twelve weeks of implantation, the transferred bone had contours more similar to the native angle (Fig. 10B) than the initial rectangular specimens (Fig. 3B) which further suggests tissue remodeling. The SG found within the reconstructed mandibular angles serves as evidence of tissue integration between the native bone and the engineered tissues; the individual SG pieces appeared smaller in size with roughened edges after twelve further weeks of implantation (Fig. 13). 
By the measurements used in this study, there were no statistically significant differences between angles reconstructed as avascular grafts or free flaps. Avascular graft techniques have resulted in success in critical-sized mandibular angle defects in sheep [21] and recruitment of local vessels to avascular grafts via growth factors significantly increased healing in large mandibular angles in goats [22]. While a defect of large volume, the mandibular angle is a relatively well-perfused area and these sheep had no other risk factors. A more stringent model, such as an irradiated defect or animal with vasculopathies, may better clarify the impact of transferring bioreactor-generated tissues as avascular grafts or vascularized flaps.

In one animal in the flap group, the transferred tissue became dislocated from the defect (Supplemental Fig. 1) into the fascia of the neck at some point within the twelve weeks between reconstruction and tissue harvest. As histological analysis of the reconstructed mandibular angle demonstrated new bone formation, it was unclear if a section or the entire flap dislocated; therefore, the mandible was still included in the histologic and radiologic analyses. The thickness and maturity of the fibrous capsule surrounding the ectopic tissue suggests earlier rather than later dislocation (Supplemental Fig. 1C). After nine weeks of growth within a bioreactor, and twelve weeks after anastomoses, the specimen continued to contain viable bone tissue despite its ectopic position in the neck fascia. While a non-optimal surgical outcome, this finding demonstrates the ability of bioreactor-generated free flaps to retain mineralization despite an unfavorable and mechanically unloaded environment.

A previous study using the same scaffold materials, bioreactors, and lead personnel resulted in a higher percentage of bioreactors containing viable mineralized $(76.9 \%$ versus $50.0 \%$ ) and greater height of produced bone (fractional depth of ranging from 0.68-1.13 versus 0.34-0.54) compared to the current study [9]. However, the current study was performed in older sheep (3-4 years) versus adolescent animals (4 months) in the previous study. The osteogenic potential of periosteum, i.e. the source of stem cells for this bioreactor system, has been shown to diminish with host age in murine and human studies $[23,24]$ and may be a cause for the 
discrepancy between studies. Large mandibular defects are also encountered in the pediatric population and the challenges in reconstruction are similar to those seen in adults [25]. Pediatric patients are significantly more likely to suffer from ankle deformity compared to adults after fibular harvest for flap transfer [26]. Given the increased periosteal osteogenic potential, as well as need for alternatives to fibular harvest, the in vivo bioreactor strategy may have even more benefits in the pediatric population.

This study had several limitations. To minimize the loss of animal life, a non-treated control group was not used. This decision was supported by the literature; ovine mandibular segmental defects smaller in length $(3.5 \mathrm{~cm})$ and a similar mandibular angle $(3 \mathrm{~cm}$ in length and $3 \mathrm{~cm}$ in height) were demonstrated to be critical-size (non-healing) [21, 27]. There was also no sham vascular surgery performed in graft groups; it is possible that incision into the neck, handling of vessels, and prolonged surgical time may have resulted in unintended differences between outcomes in graft and flap groups. While there have not been previous studies in which graft versus flap reconstruction have been directly studied in an ovine mandibular angle model to make comparisons to this study, it is possible that more differences may have been seen between groups with increasing number of animals. As one of the objectives of the study was to produce solid tissues of customizable geometry for implantation, there was no control group in which mandibular defects were treated using graft without prior bioreactor implantation. In addition, the defect chosen is under relatively little mechanical load. It was chosen given its large volume, proximity to the vessels of the neck for ease of anastomoses, and prior establishment in the literature [9, 21]. Given its high clinical relevance, increased biomechanical load, and proximity to other important craniofacial structures such as the oral mucosa, it will be critical to evaluate the success of this strategy in a mandibular segmental defect; however, an unloaded defect is still of value to evaluate osteointegration with native tissues. As this defect was biomechanically unloaded and mechanical testing of mineralized tissue is generally a destructive assay, priority was given to histologic analysis. However, as tissue mechanical 
properties are functional measurements with clinical significance in mandibular reconstruction, future studies should incorporate mechanical analysis of tissues generated from in vivo bioreactors.

This study also possessed a number of strengths. This approach was able to generate autologous mineralized tissue of custom geometry without any exogenous growth factors. With the ability to implant multiple bioreactors per animal, different biomaterials were able to be evaluated in a head-to-head fashion. In addition, tissues were functionally evaluated by transfer to a large bony defect. One of the major challenges facing tissue engineering is overcoming oxygen diffusion limitations when generating large volumes of tissue [28]. In this study, tissue constructs of up to $4 \mathrm{cc}$ in volume were generated and could maintain viability via an arterial and venous connection to the systemic circulatory system. Furthermore, by using a large animal model, treatment of a mandibular defect of clinically-relevant size was performed. Twelve weeks following reconstruction, there was integration between the transferred tissues and the native mandible and evidence of tissue remodeling.

\section{Conclusion}

To optimize high fidelity mandibular reconstruction with minimal donor site morbidity, we have investigated use of different scaffold materials to produce mineralized tissues of large volumes and customizable geometries in an in vivo bioreactor strategy. In this study, it was demonstrated in an ovine model that in vivo bioreactors filled with scaffold material and implanted against periosteum can generate large vascularized tissues without exogenous growth factors, using scaffold material of either autologous bone, synthetic graft, or a combination. Synthetic graft allowed for formation of mineralized tissue of similar quality to autologous graft, although less quantity by radiographic and histologic metrics. In this study, tissues generated within in vivo bioreactors filled with synthetic graft were successfully used to 
reconstruct large mandibular angle defects in an ovine model with no significant differences between transfer as avascular grafts or vascularized free flaps.

\section{Acknowledgements}

This work was supported by the Army, Navy, NIH, Air Force, VA and Health Affairs to support the AFIRM II effort, under Award No. W81XWH-14-2-0004. The U.S. Army Medical Research Acquisition Activity, 820 Chandler Street, Fort Detrick MD 21702-5014 is the awarding and administering acquisition office. Opinions, interpretations, conclusions and recommendations are those of the author and are not necessarily endorsed by the Department of Defense. This work was also in part supported by the Osteo Science Foundation. A.M.T. and S.R.S. would like to thank the Baylor College of Medicine Medical Scientist Training Program (NIH T32 GM007330) and A.M.T. would like to acknowledge the Barrow Scholars Program. We would like to acknowledge the help and support of Dr. Julia Goldman, Peggy Bek, the veterinary staff of the University of Texas Health Science Center at Houston, Natasja van Dijk, Vincent Cuijper, Meyke Hermsen, Brandon T. Smith, Emma Watson, Casey Rehfeld of KLS Martin, Dr. Daniel Felleman, and Mary Kay Kindred of K Bar Livestock. There are no conflicts of interest to report in this work.

\section{References}

[1] Ferreira JJ, Zagalo CM, Oliveira ML, Correia AM, Reis AR. Mandible reconstruction: History, state of the art and persistent problems. Prosthet Orthot Int 2015;39:182-9.

[2] Schrag C, Chang YM, Tsai CY, Wei FC. Complete rehabilitation of the mandible following segmental resection. J Surg Oncol 2006;94:538-45.

[3] Tatara AM, Wong ME, Mikos AG. In vivo bioreactors for mandibular reconstruction. J Dent Res 2014;93:1196-202.

[4] Warnke PH, Wiltfang J, Springer I, Acil Y, Bolte H, Kosmahl M, Russo PA, Sherry E, Lutzen

$\mathrm{U}$, Wolfart S, Terheyden $\mathrm{H}$. Man as living bioreactor: fate of an exogenously prepared customized tissue-engineered mandible. Biomaterials 2006;27:3163-7. 
[5] Weiss KR. "To B(MP-2) or Not To B(MP-2)" or "Much Ado About Nothing": Are Orthobiologics in Tumor Surgery Worth the Risks? Clin Cancer Res 2015;21:2889-91.

[6] Coletti DP, Ord R, Liu X. Mandibular reconstruction and second generation locking reconstruction plates: outcome of 110 patients. Int J Oral Maxillofac Surg 2009;38:960-3.

[7] Cheng MH, Brey EM, Allori A, Satterfield WC, Chang DW, Patrick CW, Jr., Miller MJ. Ovine model for engineering bone segments. Tissue Eng 2005;11:214-25.

[8] Finkemeier CG. Bone-grafting and bone-graft substitutes. J Bone Joint Surg Am 2002;84A:454-64.

[9] Tatara AM, Kretlow JD, Spicer PP, Lu S, Lam J, Liu W, Cao Y, Liu G, Jackson JD, Yoo JJ, Atala A, van den Beucken JJ, Jansen JA, Kasper FK, Ho T, Demian N, Miller MJ, Wong ME, Mikos AG. Autologously generated tissue-engineered bone flaps for reconstruction of large mandibular defects in an ovine model. Tissue Eng Part A 2015;21:1520-8.

[10] Miller MJ, Goldberg DP, Yasko AW, Lemon JC, Satterfield WC, Wake MC, Mikos AG. Guided bone growth in sheep: a model for tissue-engineered bone flaps. Tissue Eng 1996;2:519.

[11] Nakashima K, de Crombrugghe B. Transcriptional mechanisms in osteoblast differentiation and bone formation. Trends Genet 2003;19:458-66.

[12] Yan YB, Li JM, Xiao E, An JG, Gan YH, Zhang Y. A pilot trial on the molecular pathophysiology of traumatic temporomandibular joint bony ankylosis in a sheep model. Part II: The differential gene expression among fibrous ankylosis, bony ankylosis and condylar fracture. J Craniomaxillofac Surg 2014;42:e23-8.

[13] Yan YB, Li JM, Xiao E, An JG, Gan YH, Zhang Y. A pilot trial on the molecular pathophysiology of traumatic temporomandibular joint bony ankylosis in a sheep model. Part I: Expression of Wnt signaling. J Craniomaxillofac Surg 2014;42:e15-22.

[14] Brey EM, Cheng MH, Allori A, Satterfield W, Chang DW, Patrick CW, Jr., Miller MJ. Comparison of guided bone formation from periosteum and muscle fascia. Plast Reconstr Surg 2007;119:1216-22.

[15] Li M, Amizuka N, Oda K, Tokunaga K, Ito T, Takeuchi K, Takagi R, Maeda T. Histochemical evidence of the initial chondrogenesis and osteogenesis in the periosteum of a rib fractured model: implications of osteocyte involvement in periosteal chondrogenesis. Microsc Res Tech 2004;64:330-42.

[16] Chappard D, Guillaume B, Mallet R, Pascaretti-Grizon F, Basle MF, Libouban H. Sinus lift augmentation and beta-TCP: a microCT and histologic analysis on human bone biopsies. Micron 2010;41:321-6. 
[17] de Ruiter A, Dik E, van Es R, van der Bilt A, Janssen N, Meijer G, Koole R, Rosenberg A. Micro-structured calcium phosphate ceramic for donor site repair after harvesting chin bone for grafting alveolar clefts in children. J Craniomaxillofac Surg 2014;42:460-8.

[18] Mittra E, Rubin C, Qin YX. Interrelationship of trabecular mechanical and microstructural properties in sheep trabecular bone. J Biomech 2005;38:1229-37.

[19] Le Nihouannen D, Daculsi G, Saffarzadeh A, Gauthier O, Delplace S, Pilet P, Layrolle P. Ectopic bone formation by microporous calcium phosphate ceramic particles in sheep muscles. Bone 2005;36:1086-93.

[20] Giannoudis PV, Faour O, Goff T, Kanakaris N, Dimitriou R. Masquelet technique for the treatment of bone defects: tips-tricks and future directions. Injury 2011;42:591-8.

[21] Russmueller G, Moser D, Spassova E, Plasenzotti R, Poeschl PW, Seemann R, Becker S, Pirklbauer K, Eder-Czembirek C, Czembirek C, Perisanidis C, Ewers R, Schopper C. Tricalcium phosphate-based biocomposites for mandibular bone regeneration--A histological study in sheep. J Craniomaxillofac Surg 2015;43:696-704.

[22] Fennis JP, Stoelinga PJ, Jansen JA. Mandibular reconstruction: a histological and histomorphometric study on the use of autogenous scaffolds, particulate cortico-cancellous bone grafts and platelet rich plasma in goats. Int J Oral Maxillofac Surg 2004;33:48-55.

[23] Lu C, Miclau T, Hu D, Hansen E, Tsui K, Puttlitz C, Marcucio RS. Cellular basis for agerelated changes in fracture repair. J Orthop Res 2005;23:1300-7.

[24] Nakahara H, Goldberg VM, Caplan Al. Culture-expanded human periosteal-derived cells exhibit osteochondral potential in vivo. J Orthop Res 1991;9:465-76.

[25] Crosby MA, Martin JW, Robb GL, Chang DW. Pediatric mandibular reconstruction using a vascularized fibula flap. Head Neck 2008;30:311-9.

[26] Ling XF, Peng X. What is the price to pay for a free fibula flap? A systematic review of donor-site morbidity following free fibula flap surgery. Plast Reconstr Surg 2012;129:657-74.

[27] Kontaxis A, Abu-Serriah M, Ayoub AF, Barbenel JC. Mechanical testing of recombinant human bone morphogenetic protein-7 regenerated bone in sheep mandibles. Proc Inst Mech Eng H 2004;218:381-8.

[28] Novosel EC, Kleinhans C, Kluger PJ. Vascularization is the key challenge in tissue engineering. Adv Drug Deliv Rev 2011;63:300-11. 
Table 1. Scaffold histological scoring guide.

\begin{tabular}{|c|c|c|}
\hline Category & Score & Description \\
\hline \multicolumn{3}{|c|}{ SG Intactness } \\
\hline & 0 & No SG present \\
\hline & 1 & $\begin{array}{l}\text { Synthetic scaffold shows signs of degradation; no viable bone } \\
\text { tissue }\end{array}$ \\
\hline & 2 & Synthetic scaffold intact; no viable bone tissue \\
\hline & 3 & Synthetic scaffold intact; viable bone tissue \\
\hline & 4 & Synthetic scaffold shows signs of degradation; viable bone tissue \\
\hline \multicolumn{3}{|c|}{ SG Substrate } \\
\hline & 0 & No scaffold present \\
\hline & 1 & Scaffold present; no viable bone tissue \\
\hline & 2 & $\begin{array}{l}\text { Scaffold present; viable bone tissue on }<25 \% \text { of available scaffold } \\
\text { surface area }\end{array}$ \\
\hline & 3 & $\begin{array}{l}\text { Scaffold present; viable bone tissue on } 25-75 \% \text { of available } \\
\text { scaffold surface area }\end{array}$ \\
\hline & 4 & $\begin{array}{l}\text { Scaffold present; viable bone tissue on }>75 \% \text { of available scaffold } \\
\text { surface area }\end{array}$ \\
\hline \multicolumn{3}{|c|}{ AG Substrate } \\
\hline & 0 & No scaffold present \\
\hline & 1 & Scaffold present; no viable bone tissue \\
\hline & 2 & $\begin{array}{l}\text { Scaffold present; viable bone tissue on }<25 \% \text { of available scaffold } \\
\text { surface area }\end{array}$ \\
\hline & 3 & $\begin{array}{l}\text { Scaffold present; viable bone tissue on } 25-75 \% \text { of available } \\
\text { scaffold surface area }\end{array}$ \\
\hline & 4 & $\begin{array}{l}\text { Scaffold present; viable bone tissue on }>75 \% \text { of available scaffold } \\
\text { surface area }\end{array}$ \\
\hline
\end{tabular}


Table 2. Tissue histological scoring guide.

\begin{tabular}{lcl}
\hline Category & Score & Description \\
\hline Type & 0 & $\begin{array}{l}\text { Significant presence inflammatory cells } \\
\text { Primarily fibrovasculature tissue } \\
\text { Maturity }\end{array}$ \\
& 2 & Presence of any amount of viable bone tissue \\
& 0 & No viable bone tissue \\
1 & Presence of any viable osteoid \\
2 & Presence of any viable woven bone \\
3 & Presence of any viable lamellar bone \\
\hline Presence of Osteoclast-like Cells \\
\hline 0 & No osteoclast-like cells observed \\
& Osteoclast-like cells observed \\
\hline
\end{tabular}


Figure 1. Empty bioreactors. (A) Top view (implanted orientation). (B) Bottom view (open face adjacent to periosteum). (C) Ethylene-vinyl acetate cuff with bioreactor chamber removed (side view). Note the ability of the cuff to hold suture (arrow). (D) Bioreactor chamber (side view) with removed cuff. Scale bar $=10 \mathrm{~mm}$

Figure 2. Gross surgical photographs: $f=$ flap; $n b=$ native bone; and $p=$ pedicle. $(A)$ Mix bioreactor filled with a 50/50 v/v mixture of $A G$ and $S G$ before implantation against the periosteum of the rib. (B) After nine weeks, the bioreactors were removed to reveal vascularized tissues in the shape of the bioreactor. (C) These tissues could be harvested as vascularized flaps with pedicles, or as avascular grafts of custom geometry. (D) $3 \mathrm{~mm}$ biopsies of the soft tissue envelope surrounding the tissues were harvested for RT-qPCR analysis. (E) A large (4 cm in length, $1 \mathrm{~cm}$ in height) defect was created in the right mandibular angle. (F) Using tissue from an SG bioreactor, this defect was reconstructed as an avascular graft $(n=3)$ or vascularized free tissue flap $(n=3)$. After an additional twelve weeks, animals were euthanized and the mandibles were harvested.

Figure 3. Representative bioreactor specimen (A) microCT reconstructions after thresholding and $(B)$ histological sections. Scale bar $=2 \mathrm{~mm}$.

Figure 4. Mean microCT measurements of bioreactor specimens ( $n=6$ per group) for (A) bone volume/total volume (\%BV/TV), (B) trabecular number (Tb.N.), (C) trabecular spacing (Tb.Sp.), and (D) trabecular thickness (Tb.Th.), where error bars represent standard deviation. Those that do not share the same letter are statistically significantly different $(p<0.05)$.

Figure 5. Representative high magnification histological images of bioreactor specimens with viable bone from the (A) AG group, (B) Mix group, and (C) SG group: $S G=$ Synthetic Graft; $A G=$ Autograft; ${ }^{*}=$ new viable mineralized tissue. $S G$ group. Scale bar $=100 \mu \mathrm{m}$.

Figure 6. Representative high magnification histological images from bioreactor specimens comparing mineralized tissues to fibrovascular tissues: SG = Synthetic Graft; $\mathrm{AG}=$ Autograft; ${ }^{*}=$ new viable mineralized tissue; $\mathrm{fr}=$ fibrous tissue; and black arrow = cartilaginous tissue. (A) Both SG and AG were capable of supporting new bone tissue. (B) No new mineralized tissue was observed in some bioreactors. (C) Cartilaginous regions (black arrow) were occasionally observed at the border between mineralized tissue and fibrous tissue. Scale bar $=100 \mu \mathrm{m}$.

Figure 7. Quantitative histological scoring results. The top row contains the scaffold scores, including (A) SG Intactness, (B) SG Substrate, and (C) AG Substrate scores. The bottom row contains the tissue scores, including (D) Type, (E) Maturity, and (F) Presence of Osteoclast-like Cells. ${ }^{*}=$ statistically significant differences $(p<0.05)$.

Figure 8. Histomorphometric analysis (n beneath each group) reported as mean with error bars representing standard deviation, except where $n=2$, where the error bar represents range. (A) Fractional depth of bioreactors determined to contain viable new 
bone. (B) SG Surface Area and (C) Bone Surface Area of bioreactor specimens after 9 weeks of implantation against the rib periosteum. Those that do not share the same letter are statistically significantly different $(p<0.05)$.

Figure 9. RT-qPCR analysis $\left(\Delta \mathrm{C}_{t}\right)$ of Runx2 and $O C$ expression in the soft tissue envelope generated around tissues within the in vivo bioreactors after 9 weeks of implantation (top $=$ white, bottom $=$ gray), as well as periosteum harvested from ribs not used for implantation (black). Not pictured: relative expression of biopsies taken from the side of bioreactors (Supplemental Table 1). Gene expression has been normalized to GAPDH and is shown as mean + standard error. There were no statistically significant differences between any groups $(p<0.05)$. 
Figure 10. Representative mandibular angle specimen (A) microCT reconstructions after thresholding and (B) histological sections (coronal plane). All reconstructions (graft and flap) were performed with tissues generated in SG-filled bioreactors after nine weeks of implantation against the periosteum. Scale bar $=2 \mathrm{~mm}$.

Figure 11. Mean microCT measurements of mandibular angle specimens $(\mathrm{n}=6$ for control group, $n=3$ for graft and flap groups) for (A) bone volume/total volume (\%BV/TV), (B) trabecular number (Tb.N.), (C) trabecular spacing (Tb.Sp.), and (D) trabecular thickness (Tb.Th.), where error bars represent standard deviation. Those that do not share the same letter are statistically significantly different $(p<0.05)$.

Figure 12. Comparison of mean microCT measurements of tissues generated from SG bioreactors after nine weeks of implantation against the periosteum ( $S G ; n=6$ ) followed by twelve weeks of implantation in a mandibular defect with as avascular grafts (Graft; $n=3$ ) or vascularized free tissue flaps (Flap; $n=3$ ). Measurements include $(A)$ bone volume/total volume (\%BV/TV), (B) trabecular number (Tb.N.), (C) trabecular spacing (Tb.Sp.), and (D) trabecular thickness (Tb.Th.), where error bars represent standard deviation. Those that do not share the same letter are statistically significantly different $(p<0.05)$.

Figure 13. Representative high magnification histological image from a reconstructed mandible (SG = Synthetic Graft). After twenty-one weeks of total implantation (nine weeks against the rib periosteum and twelve weeks in the mandibular angle), SG was still present. Scale bar $=100 \mu \mathrm{m}$.

Figure 14. Histomorphometric analysis (n beneath each group) reported as mean with error bars representing standard deviation of angle height of contralateral (left) angle and reconstructed (graft or flap) right angle. There were no statistically significant differences between any groups $(p<0.05)$.

Supplemental Figure 1. (A) During necropsy, a flap (white arrow) was found to have been dislocated into the neck of one animal. (B) A plain film x-ray was taken of the hemi-mandible to confirm radio-opacity of the dislocated tissue (white arrow). (C) Histological sections demonstrated viable bone within a thick fibrous capsule. Scale bar $=2 \mathrm{~mm}$. 


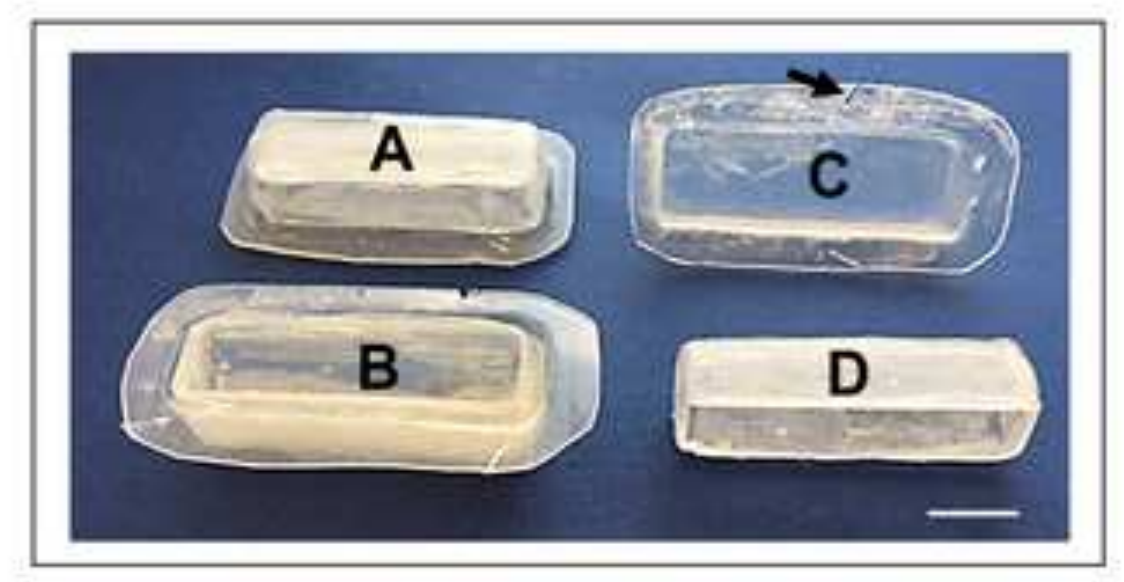

Figure 1

Figure 

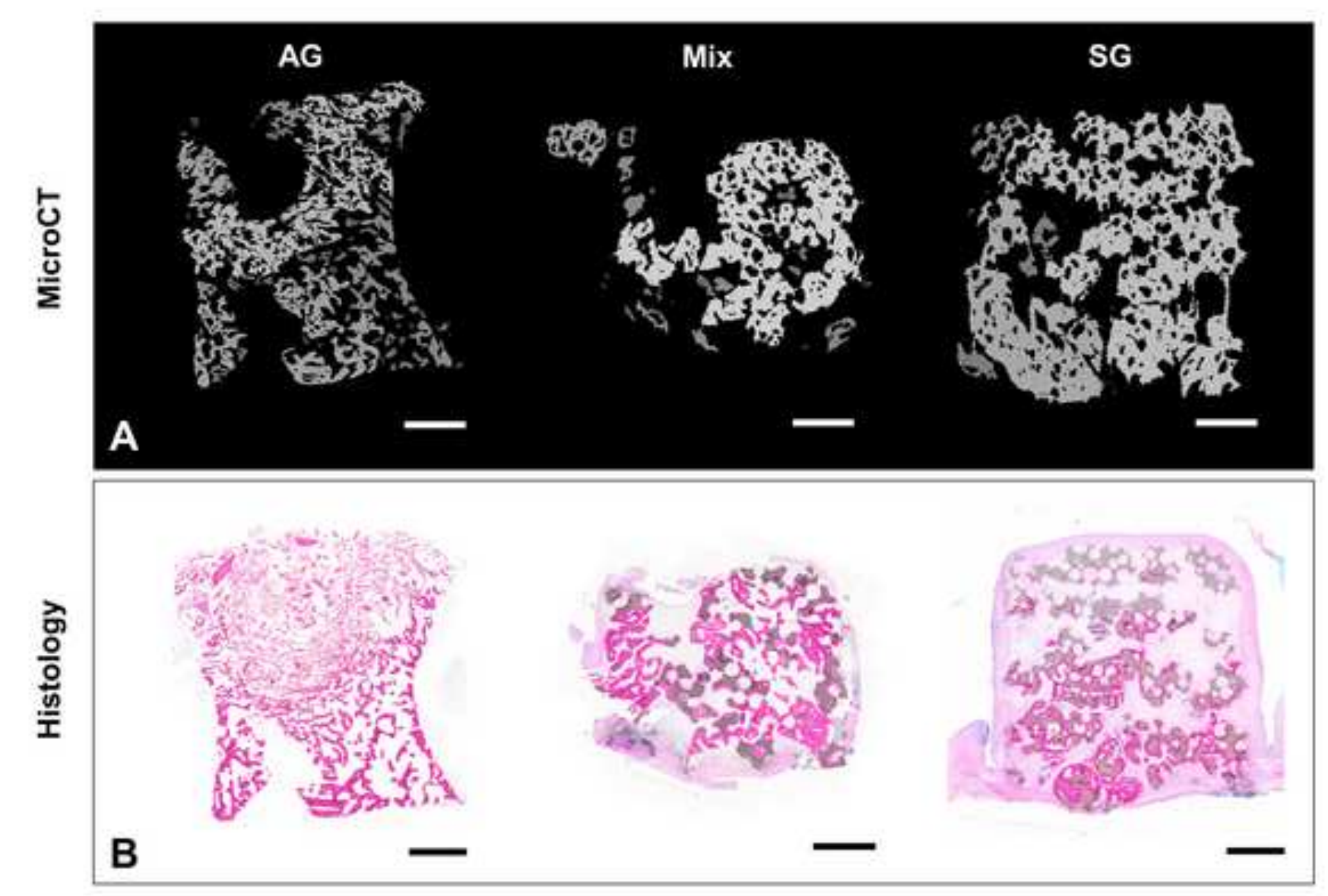


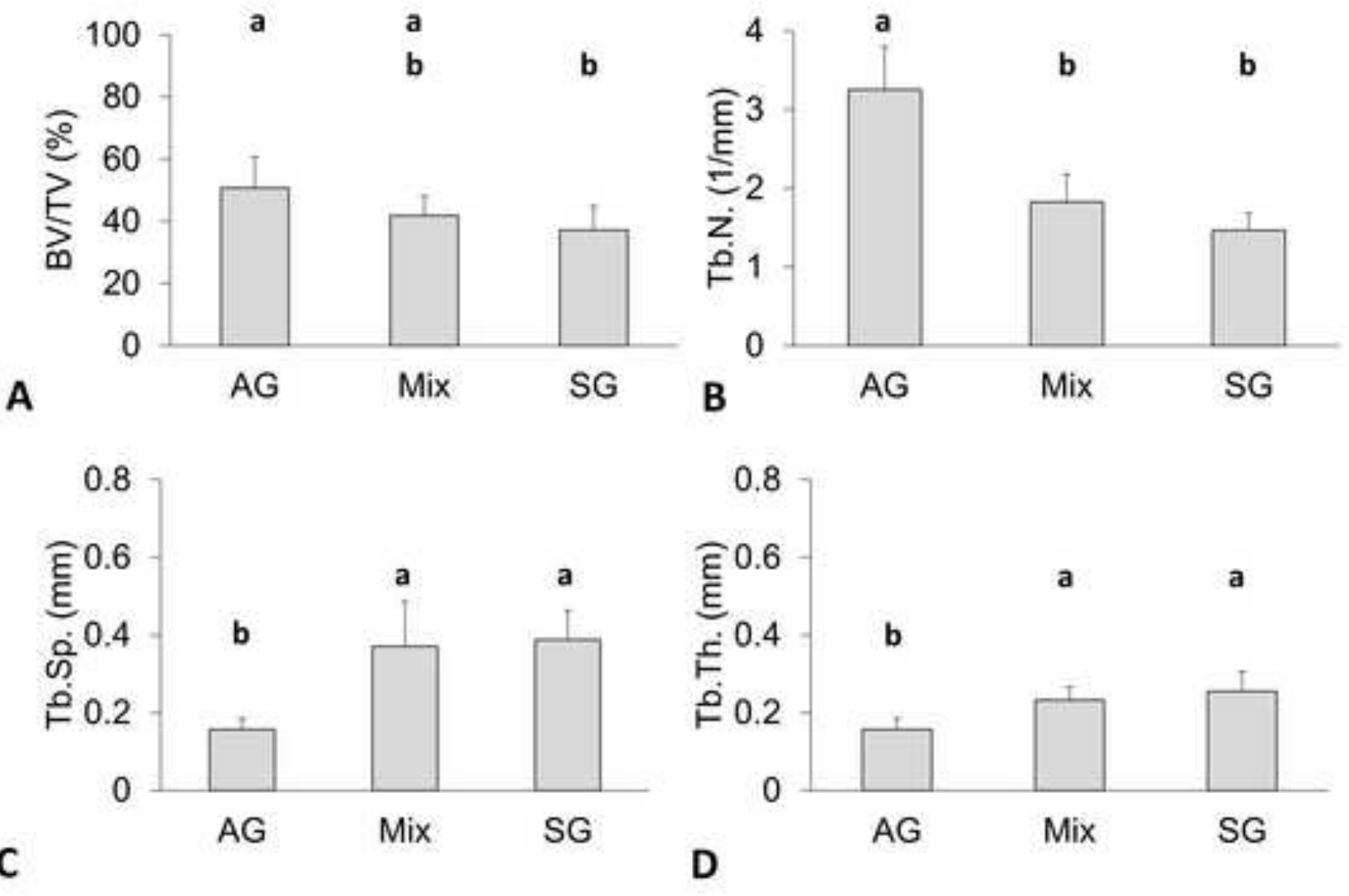



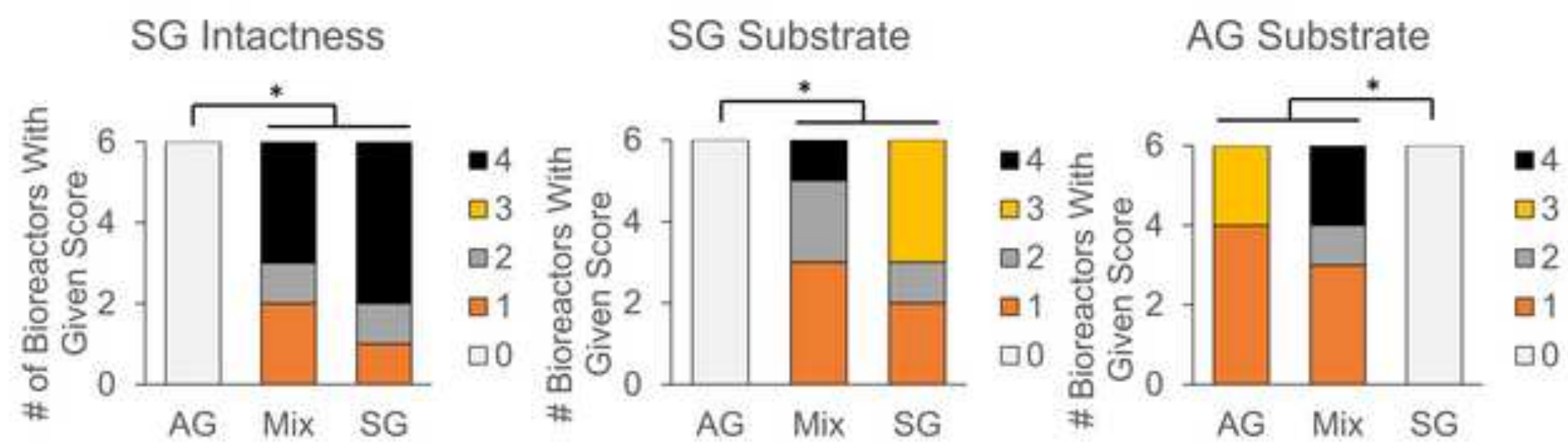

A

Type

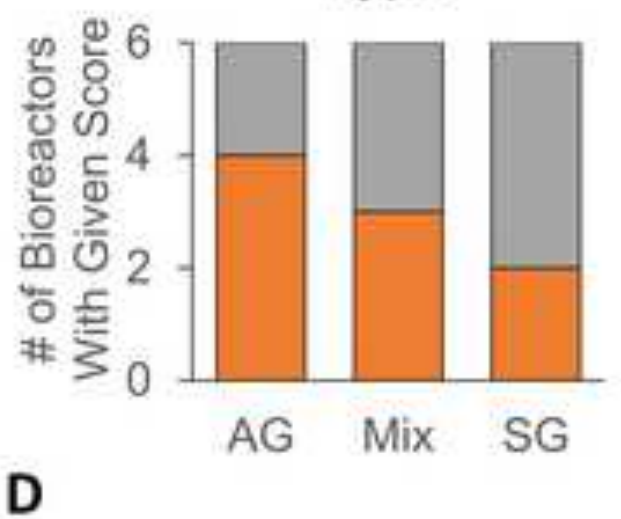

B

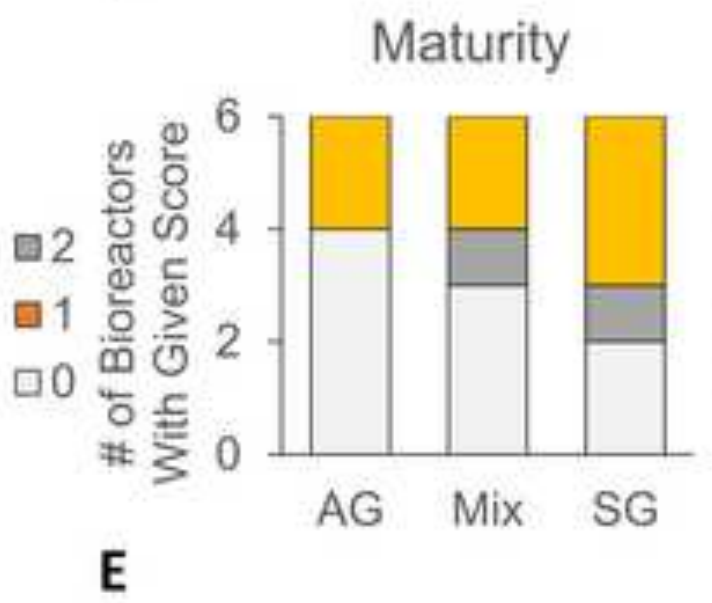

C

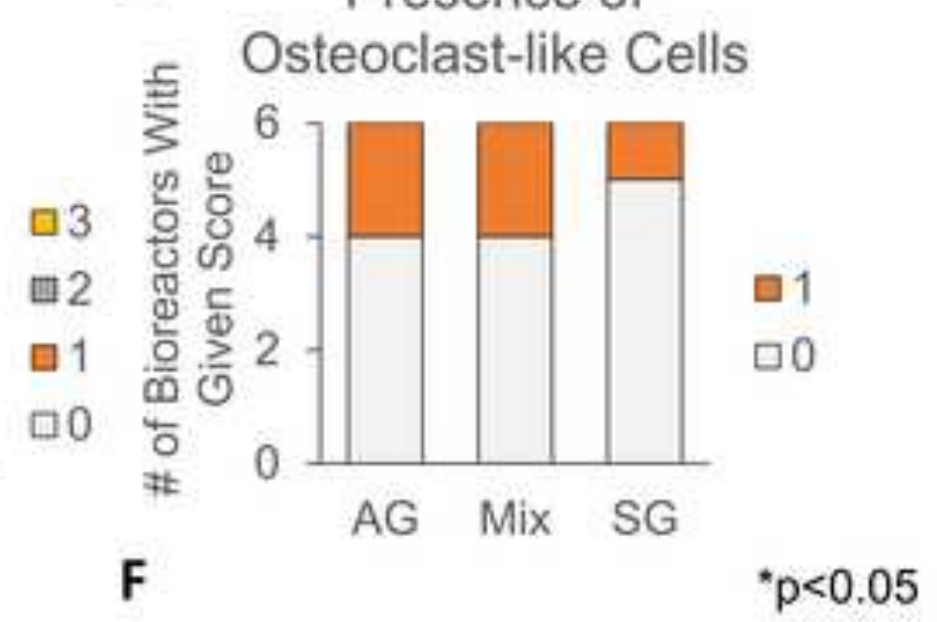




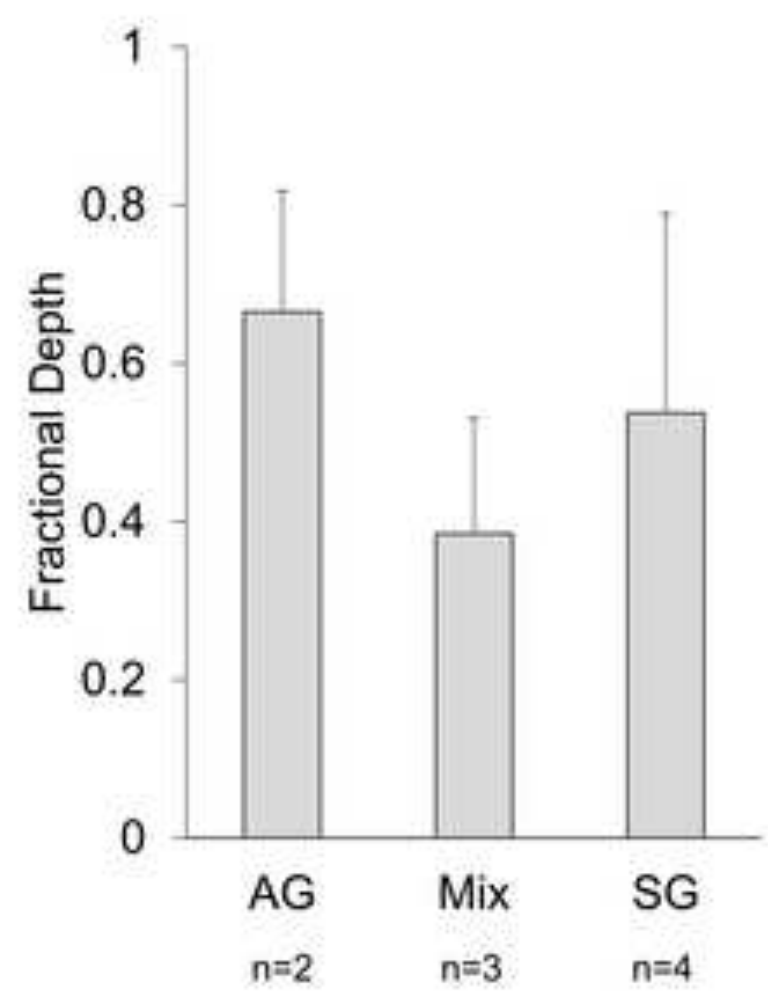

A

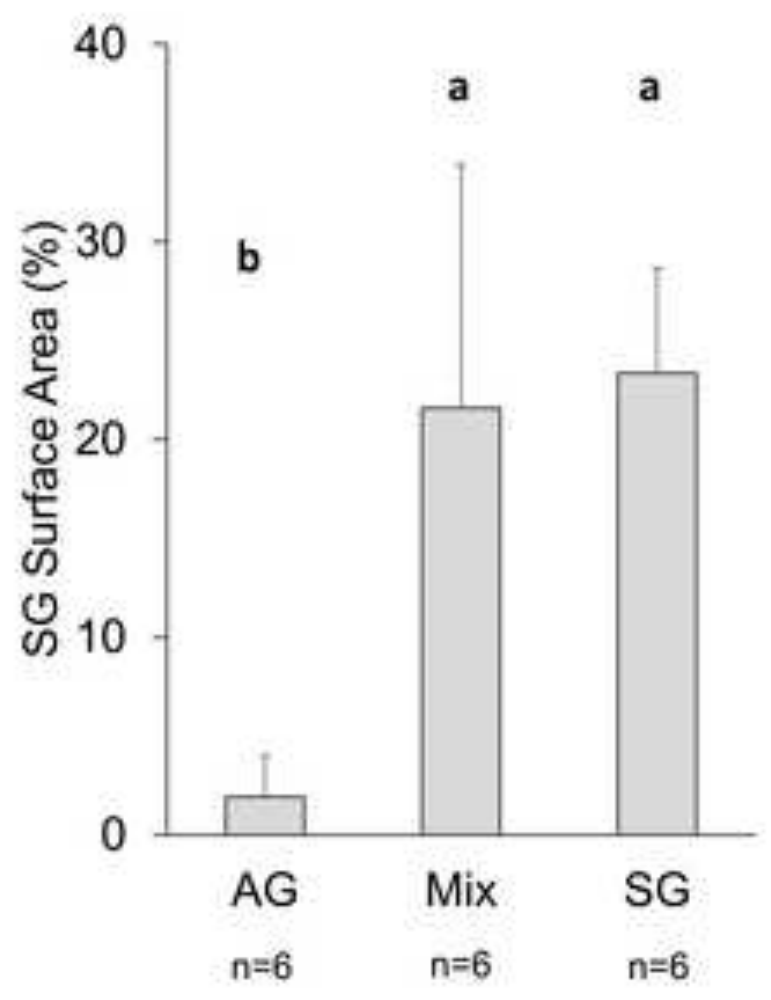

B

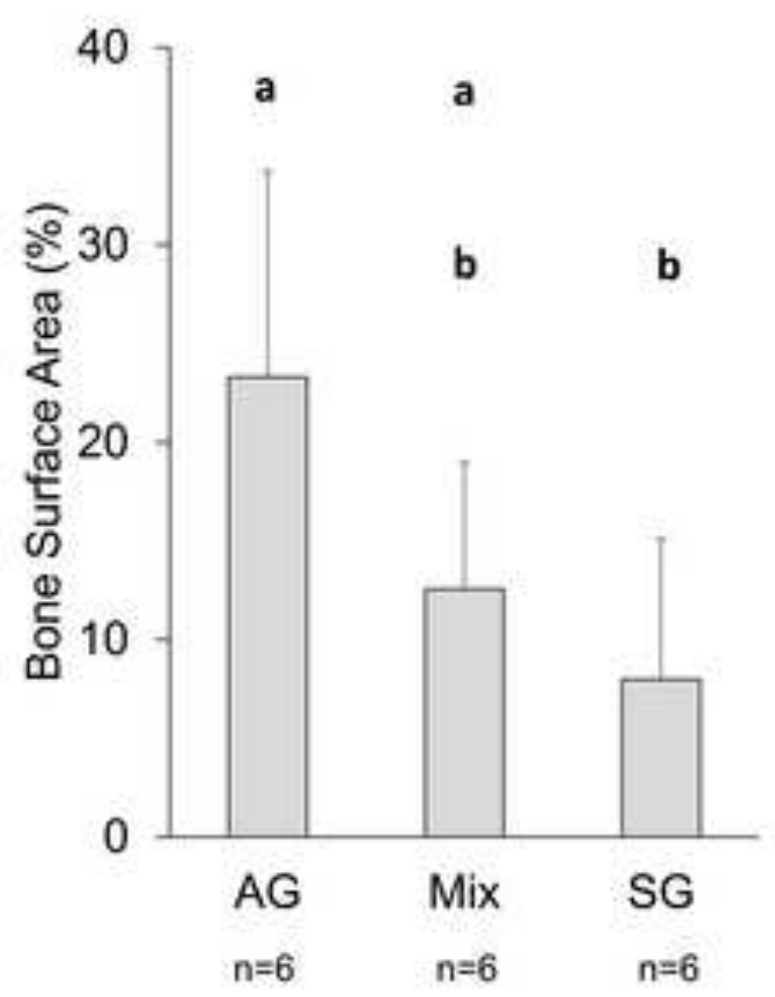

C 

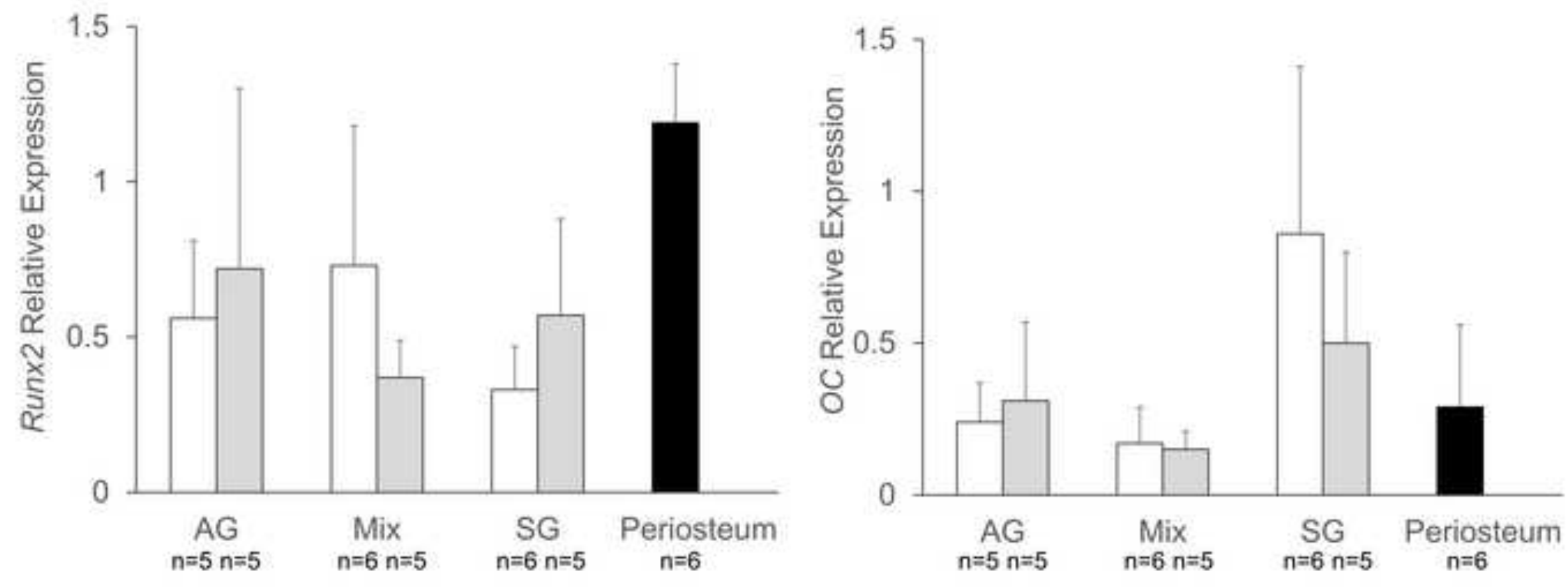

A

口Top $\square$ Bottom

B

$\square$ Top $\square$ Bottom 

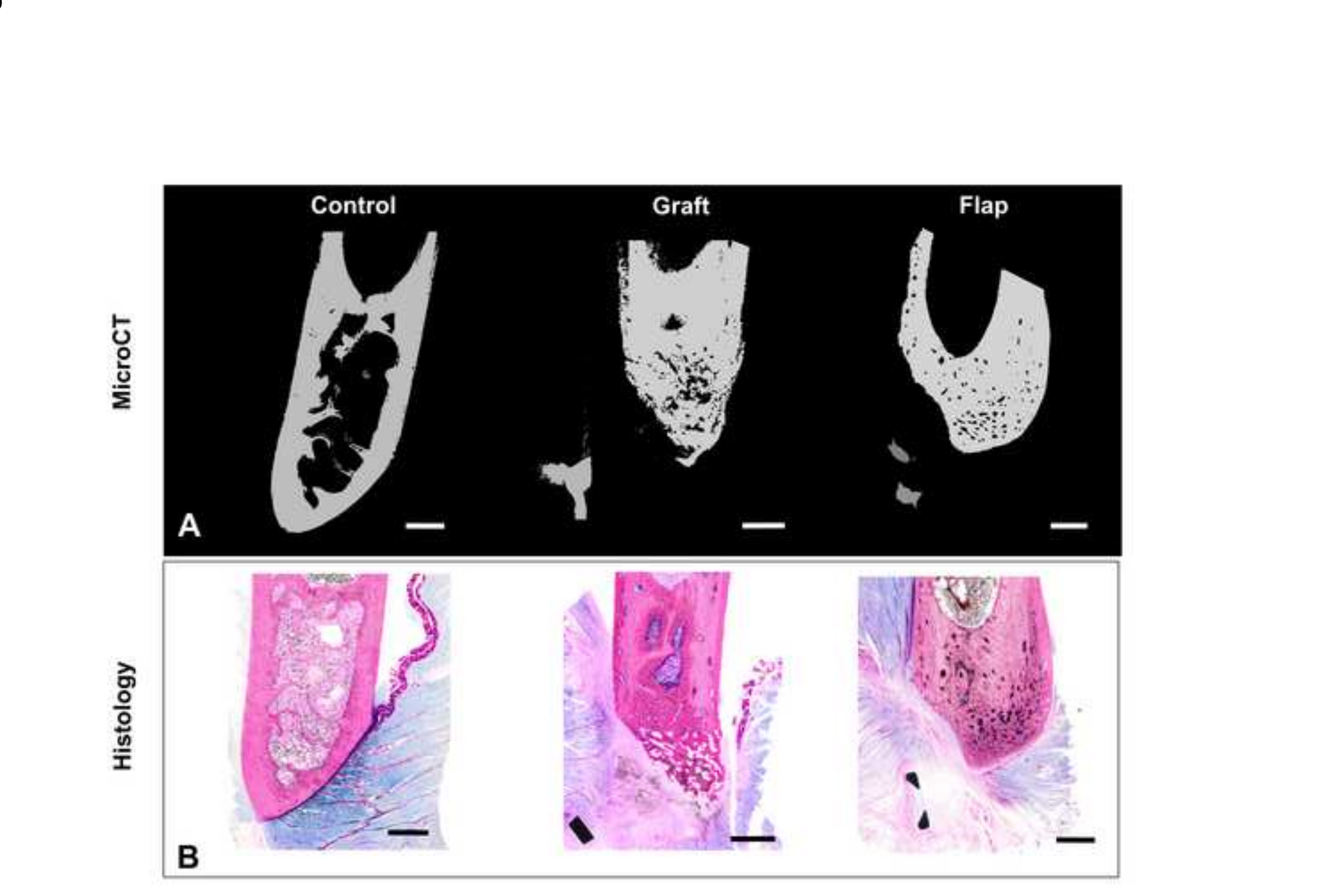

.

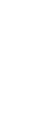



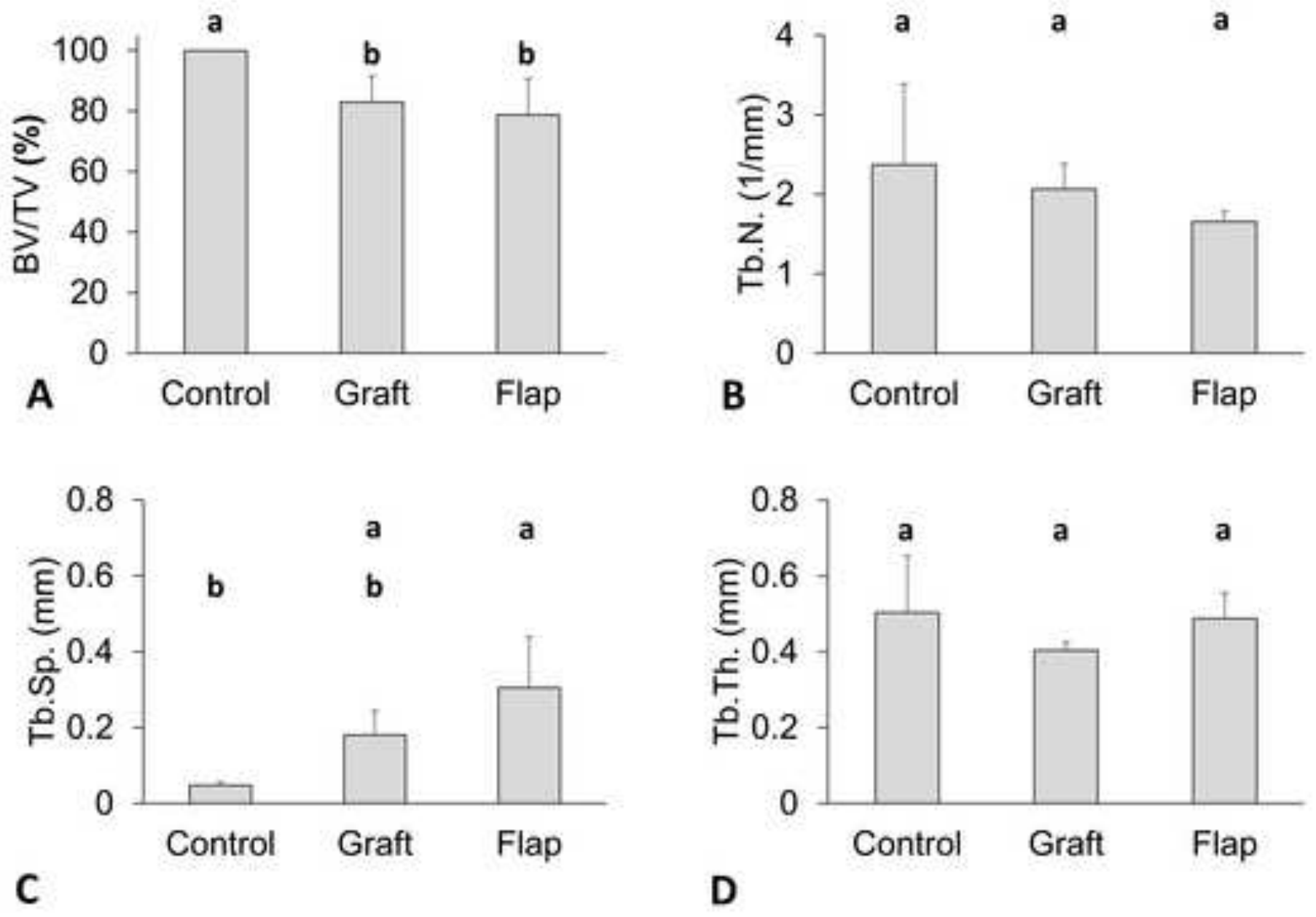

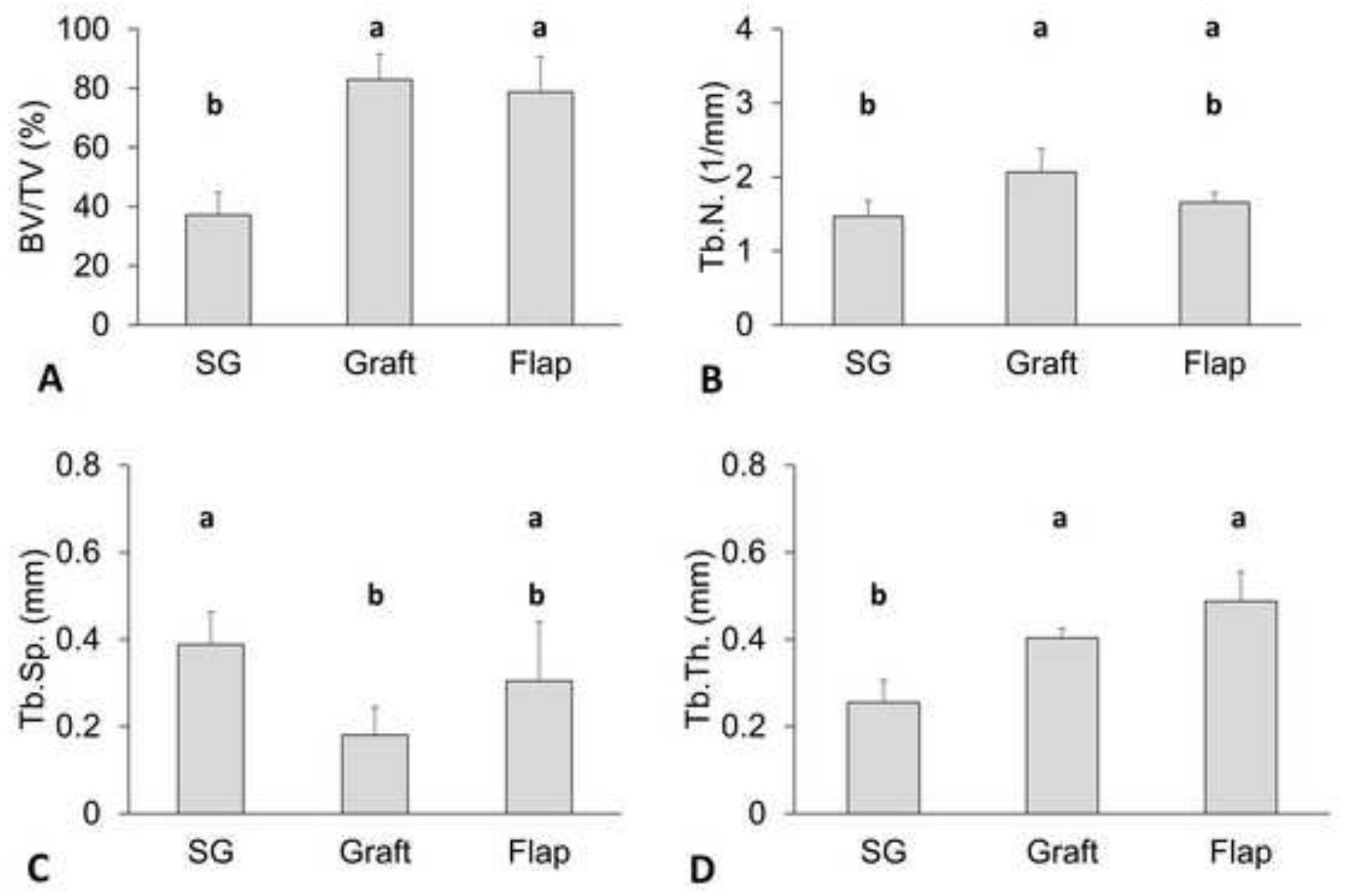


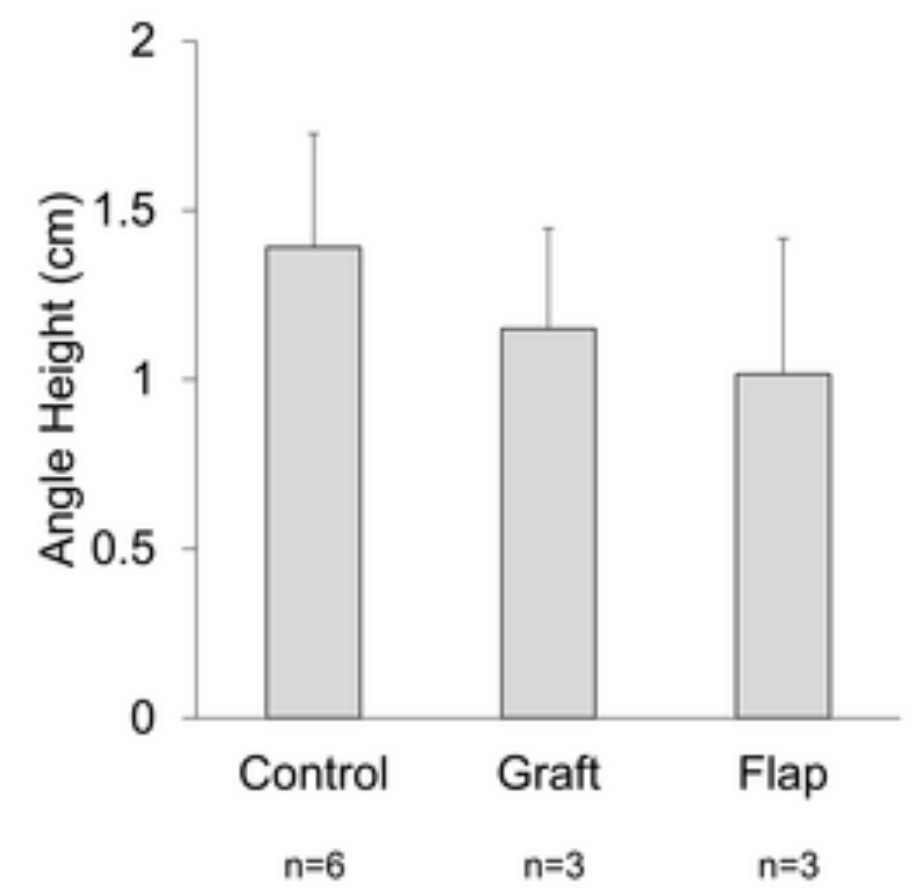




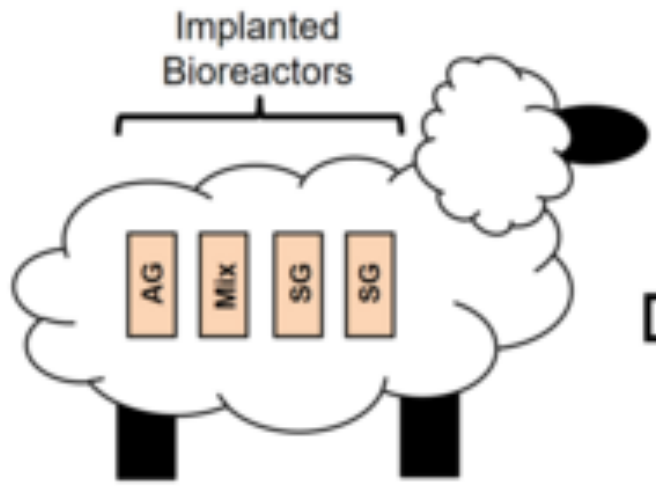

AG = Autograft: $S G=$ Synthetic Graft; $M i x=50 / 50$ v/V AG/SG

Implantation

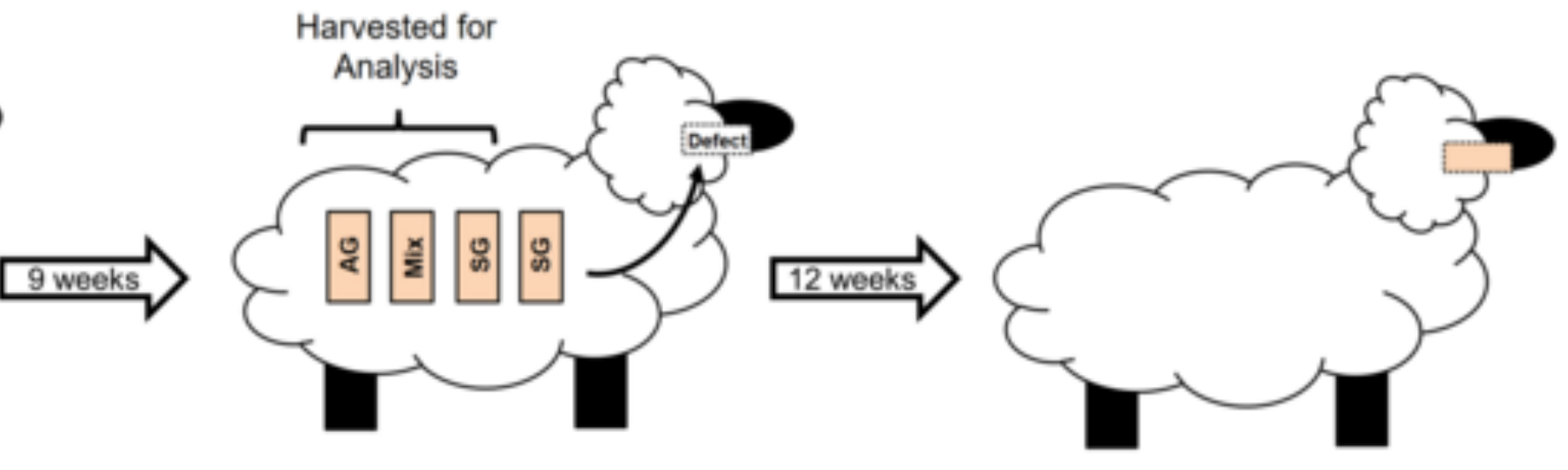

Reconstruction
Integration 